\title{
Assessment of heavy metal and metalloids pollution in soils and groundwater in Akkar Northen Lebanon
}

\author{
Ahmad Moustafa $^{1,2}$, Mariam Hamze ${ }^{1}$, Moomen Baroudi ${ }^{1}$ \\ ${ }^{1}$ Department of Environmental Biotechnology, Biotechnology Laboratory, Lebanese University, Doctoral school-AZM Center for research in biotechnology and \\ its application, Tripoli, Lebanon. \\ ${ }^{2}$ Department of Health and Environment, Laboratory of Sciences and Water Environment, Lebanese University, Faculty of public health section III, Tripoli, \\ Lebanon.
}

Correspondence Author: Moomen Baroudi, Department of Environmental Biotechnology, Biotechnology Laboratory, Lebanese University, Doctoral schoolAZM Center for research in biotechnology and its application, Tripoli, Lebanon

E-mail:- ahmed.mahmoud@ feng.bu.edu.eg; ahmedcivil2003@yahoo.com

Received date: 11 August. 2019, Accepted date: 11 Nov. 2019, Online date: 1 December 2019

Copyright: 2019 () Ahmad Moustafa et al, This is an open-access article distributed under the terms of the Creative Commons Attribution License, which permits unrestricted use, distribution, and reproduction in any medium, provided the original author and source are credited.

\begin{abstract}
Heavy metals pollution in agriculture area is highly concerned as water and soil easy up take of heavy metal can ultimately affect consumers. Akkar, situated in the northern coastal plain of Lebanon, its soil and groundwater are contaminated by pesticides and nitrates. The objectives of this study are to evaluate the trace metals found in Akkar's groundwater and soil. Duplicate samples from groundwater (12 sites) and soil (5 sites) were collected in 2017 from this area. Dissolved oxygen (DO), potential hydrogen (pH) and electrical conductivity of groundwater samples were measured. Trace metals (Cadmium, Lead, Copper, Zinc and Manganese) from groundwater samples were analyzed by spectrometry atomic absorption AAS500 supported with flame and graphite furnace method. The soil samples were digested with Nitric acid-hydrogen peroxide-Hydrochloric acid by successive heating in a block heating, and the trace amounts of Cadmium, Lead, Copper, Zinc, Manganese, Chromium, and Nickel was analyzed by inductively-coupled plasma atomic emission spectroscopy (ICP-AES). The intensity of pollution was estimated using the Heavy Metals Pollution Index (HPI) and the Heavy Metals Evaluation Index (HEI) for groundwater. The soil contamination index Enrichment Factor (EF) and Geoaccumulation Index (Igeo) were calculated. Slight contamination with $\mathrm{Ni}, \mathrm{Cu}, \mathrm{Zn}$, and $\mathrm{Cr}$ was observed with low Igeo and $\mathrm{EF}$ values in the soil. Cadmium was found to be the heaviest pollutant with EF exceeding 25, whereas lead was the second most important pollutant with an Igeo between 2 and 3 , this indicate that the soil is moderate to heavily contaminated in this area. The results showed that in groundwater, the average concentrations of the metals $\mathrm{Pb}, \mathrm{Cd}$, and $\mathrm{Cu}$ were $3.3,2.6,0.7, \mu \mathrm{g} / \mathrm{l}$ respectively. According to the water quality index (HPI) the groundwater of some studied sites like Tal Anadi and Tall Abbas Al Charki are not safe for drinking and/or cooking. The revelations during the present study summons attention from the local authorities and farmers to optimize utilization of agriculture fertilizers and pesticides, and stop using wastewater for irrigation.
\end{abstract}

Keywords: Heavy metals, Groundwater, Soil, Pollution, Akkar.

\section{INTRODUCTION}

Toxic pollutants, such as trace metals, have dramatically increased and attracted global attention because of its abundance, persistence and environmental toxicity [1]. Although these metals are natural constituents of the Earth's crust and are present in all ecosystems [2], they enter into the environment as a result of urbanization and industrial activities such as vehicle exhaust, waste disposal, sewage, and industrial emission [3]. They can also enter by a bio-geochemical process and agricultural activities [4], through impurities in agrochemicals including pesticide and fertilizer application [5], irrigation with contaminated water [6][7], sewage sludge, and livestock manures [8]. Moreover, atmospheric and weathering cycling [9], surface runoff, and groundwater flow [10] can move trace metals from different sources into the soil and water [11]. Once these trace metals reach the soil it can reduce the diversity of bio-communities, affect agricultural productivity, and pose toxic effects on crops and plants [12][13]. Also, these trace metals dispersed into the environment can accumulate in the vegetables, fish, and animal. The humans are exposed to the trace elements directly via inhalation or dermal contact or indirectly via the consumption of contaminated water and food. 
Moreover, [14] mentioned that the sources of consumed water (e.g., surface water, groundwater) are likely to be polluted by trace amounts of heavy metals which have generally high toxicity even in trace levels, they could be hazardous to human health and ecosystems [15][16].

The rapidly increasing population in urban areas led to anthropogenic activities and fossil fuel combustion. Emissions from road traffic, industry, agriculture, sewage sludge, and waste incineration are the chief sources of air and water pollution in Lebanon [17][18].

Lebanon is a part of the carbonate platform in the Eastern Mediterranean with a large coastline [19], when the majority of industries release hazardous wastes (e.g., pesticides, heavy metals, waste oil, resins and paints) into the environment with little or no prior treatment causing severe environmental pressures [18]. Untreated effluent wastes impact water and soil quality when discharged into rivers and streams or through sewer networks that infiltrate through the fractured bedrocks reaching the groundwater system [20]. Characterized by a high proportion of agricultural land in the Middle East and abundant water resources [21], Lebanon has 321580.1 hectare of land, cultivated during both seasonal crops (e.g., cereals (44\%), vegetables (36\%)) and permanent crops (e.g., olives (43\%), stone fruits (17\%)). Total irrigated lands increased to 112.954 .7 hectares in 2010 (about (9\%)) [18]. This put Lebanon's water resources under stress since irrigation water is provided mainly from groundwater.

Water quality in Lebanon is influenced by various anthropogenic factors including agricultural, domestic and industrial wastewater discharges [22][23]. Moreover, raw wastewater is being reused for irrigation in several regions of Lebanon such as in Akkar [24]. Akkar, the 2nd Lebanese agricultural zone after Bekaa plain, is highly contaminated by prohibited products. Many studies showed severe contamination of Akkar plain groundwater and soil by nitrate, nitrite, and pesticides [25][26][27]. According to [21], the coastal waters, in Akkar, are contaminated by industrial wastewater discharges. Also, a clear connection between groundwater pollution and drinking water quality was found [21]. Significant amounts of this untreated wastewater may percolate to the shallow groundwater from cesspools especially in the inland villages [20].

But to date, no scientific research regarding heavy metals pollutions in Akkar's groundwater. Based on these, the objectives of this study are to evaluate the underground water parameters; and to assess the traces metals pollution status in groundwater on 12 sites and determine the contamination level of metals in five soil samples in Akkar.

\section{MATERIAL AND METHODS}

\section{Study area}

Lebanon with a coastline length of $210 \mathrm{~km}$ along the sea [19], is characterized by the presence of Akkar plain localized in North near Syrian borders $\left(34.5506^{\circ} \mathrm{N}, 36.0781^{\circ} \mathrm{E}\right)$.

The geological map of Akkar varies widely from quaternary colluvial, sand and lake deposits to fluvial deposits; volcanic rocks and non-clastic Mesozoic sedimentary rocks [28]. The majority of the land is karst, mainly made up under limestone formations. The soil of Akkar is characterized by a neutral $\mathrm{pH}$, and $15.8 \%$ of organic matter which, it is polyhedral, clay textured, and brown in color [26][29]. They can be considered as brown Mediterranean soils where the erosion is intense and the soils formed are young and shallow, with a poorly developed structure [30][31].

However, due to the formation and development of rocky desertification, the karst system has little or no soil cover, which leads to poor filtration, and rapid infiltration [32]. The phreatic zone which supplies the wells is at low depth $(<20 \mathrm{~m})$. Also, the effects of high levels of precipitation in Akkar are dependent on the permeable soil properties [33]. Therefore, the characteristics of this area (color, size, depth and soil conditions) are permeable to pollutants' transport making this aquifer extremely vulnerable to pollution and anthropogenic impacts [34].

For this study, the sampling network was limited to twelve most vulnerable sites: Koubet Bchamra (1), Mkaytaa (2), Qaabarin (3), Tall Mehyen (4), Ballanet El Hissa (5), Al Hissa (6), Tal Andi (7), Al Chaykh Ayach (8), Tal Biri (9), Tal Abbas El Gharbi (10), Kwaykhat, (11) and Tal Abbas El Charki (12). Groundwater and soil samples were collected in September 2017. Geographical locations of the sampling sites according to Lebanon and the Middle East region are presented in figure1.

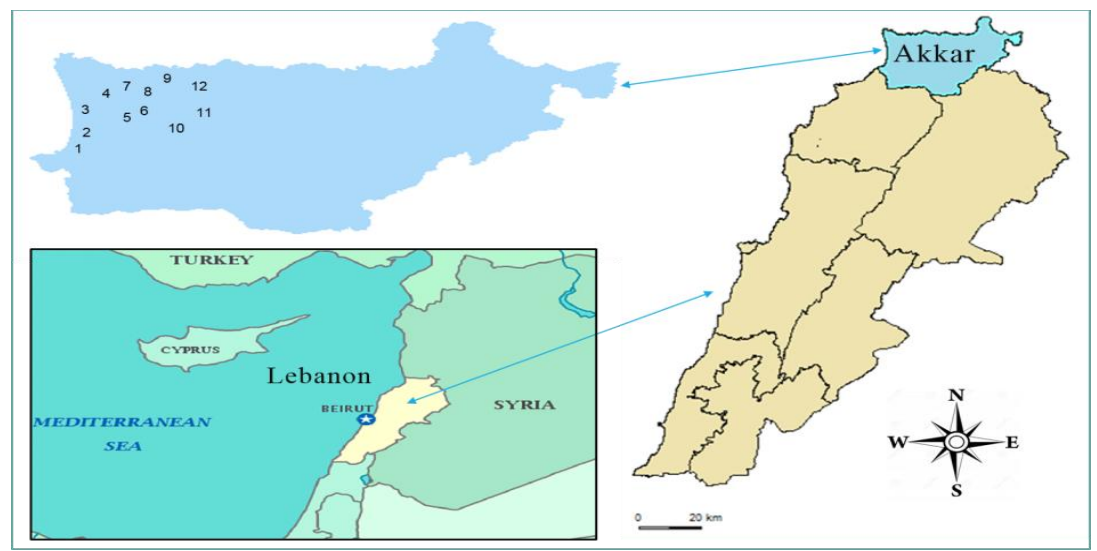

Figure 1: Study area according to Lebanon and the Middle East region.

\section{Sampling methods}

Groundwater samples were collected using $100 \mathrm{~mL}$ clean Teflon bottles. Before each collection, groundwater was pumped for 10 minutes using the drilling pump installed for each well and Teflon bottles were rinsed three times with the well's water. 
Samples were immediately stored at $4^{\circ} \mathrm{C}$ in ice boxes for transport and were then stored under refrigeration until analyzed (within 48 hours from sampling).

Surface soil samples 2-5 cm deep were collected by a made bailer at five sites (Koubet Bchamra (1), Mkaytaa (2), Al Hissa (6), Tal Andi (7), and Tal Abbas (12). The samples were homogenized and then placed in a plastic sac within a maximum of 12 hours. The samples were dried at room temperature under the hood, protected from light, and covered by a plastic cover to minimize all sources of contamination and degradation (atmospheric deposition, photolysis ...). Dry sediments were lightly ground in an agate mortar, homogenized and then sieved to pass $63 \mu \mathrm{m}$ through a nylon sieve to remove the large debris.

\section{Analytical procedure}

For analyses, a pH and conduct meter Thermo Scientific equipment with a combined electrode was used. Dissolved oxygen was measured using a device of land WTW multiline F/SET3. All chemicals and gas were supplied from Alfa Aesar Gmbh \& Co KG., Germany.

Trace metals were analyzed by spectrometry atomic absorption AAS500 equipped with several lamps for specific detection, supported with a graphite furnace method for the detection of (Cadmium $(\mathrm{Cd})$, Lead $(\mathrm{Pb})$, and Copper $(\mathrm{Cu})$ ) and flame method for the detection of (Manganese (Mn) and Zinc ( $\mathrm{Zn})$ ). Nitrous oxide, acetylene, and argon were used as carrier gas at a constant flow rate of $1900 \mathrm{~mL} / \mathrm{min}$. Metals concentrations were determined relative to a specific standard for each metal. Five calibration solutions ranging from $0.10 \mu \mathrm{g} / \mathrm{L}$ to $3000 \mu \mathrm{g} / \mathrm{L}$ were prepared from stock solutions using ultrapure water and acidified by supra pure nitric acid $0.1 \%$. Glassware was washed with detergent (Decon, King of Prussia, USA), was previously soaked in $10 \%$ (v/v) nitric acid solution for $24 \mathrm{~h}$ and rinsed with ultrapure water and was dried prior to use. Water samples were filtered through a 0.45 $\mu \mathrm{m}$ particle retention glass filters. The filtered sample was injected automatically.

All metals analyses were replicated and presented as the relative standard deviation (ratio between the mean and the standard deviation of the replicated measurements) lower than $10 \%$. The sensitivity was checked using the concentration of standard multiple by 0.0044 and divided by the absorption value.

For ETM analysis, the fine-grained fractions were recovered by sieving. Only the particles of a size fraction less than $63 \mu \mathrm{m}$ were used for trace metal analysis this fraction has the affinity and ability to retain the largest trace metals [35].

The dry samples were then digested with Nitric acid, hydrogen peroxide, Hydrochloric acid by successive heating in a block heating (Hot block) according to US EPA method 3050B [36]. The solution was then diluted with ultrapure Milli-Q water and filtered through a $0.45 \mu \mathrm{m}$ cellulose acetate membrane. Mineralization was performed in duplicate, and the calculated standard deviations show on average a good reproducibility.

The data quality was controlled this mineralization protocol has been validated by analysis of certified sediment attacks (HISS and MESS) of the National Research Council of Canada. Accuracy was within 5\% of the certified values and the analytical error (relative standard deviation) was better than 5\% for concentrations ten times higher than detection limits. After mineralization, the total contents of the elements $\mathrm{Pb}, \mathrm{Cd}, \mathrm{Zn}, \mathrm{Ni}, \mathrm{Cr}$, and $\mathrm{Cu}$, were analyzed by inductively-coupled plasma atomic emission spectroscopy (ICP-AES) (Varian, Axial view VistaPro).

\section{Water quality parameters}

\section{RESULTS AND DISCUSSION}

The physicochemical parameters of the groundwater samples such as dissolved oxygen (DO), potential hydrogen (pH), and conductivity are presented in Table 1 . The importance of these parameters is in their significant effect on the water quality. For the different sampled situations, $\mathrm{pH}$ values are relatively constant, ranging from 6.71 to 7.48 (Variability <0.8). As was expected the highest value of DO (5.82mg/l) was recorded at Tal Mehyen, whereas the lowest value of DO (3.7 mg/l) was observed at Koubet Bchamra. These results are in agreement with data reported by [25], for the same area, and could be due to the high rate of decomposition of organic matter, coming from the intensive use of nitrate, pesticide in this layer [37]. The EC indicates the degree of mineralization and is a simple method for the detection of the presence of probable pollution. The average conductivity in the present study was $965.6 \mu \mathrm{s} / \mathrm{cm}$ (Table 1). This high value maybe is due to the high presence of natural minerals and organic pollutants in this area [19][25].

Table 1: Physicochemical parameters of groundwater samples at each site.

\begin{tabular}{|c|c|c|c|c|c|c|c|}
\hline \multirow{2}{*}{$\mathbf{N}^{\circ}$} & \multirow{2}{*}{ Site Names } & \multirow{2}{*}{$\begin{array}{c}\mathrm{DO} \\
(\mathrm{mg} / \mathrm{L})\end{array}$} & \multirow{2}{*}{ pH } & \multirow{2}{*}{$\begin{array}{c}\text { Conductivity } \\
(\mu \mathrm{S} / \mathrm{cm})\end{array}$} & \multicolumn{2}{|c|}{ GPS Coordinates } & \multirow{2}{*}{$\begin{array}{c}\text { Depth } \\
\text { (m) }\end{array}$} \\
\hline & & & & & Latitude & Longitude & \\
\hline 1 & KoubetBchamra & 3.72 & 6.81 & 669 & $34^{0} 32^{\prime} 37^{\prime \prime} \mathrm{N}$ & $36^{0} 00^{\prime} 06^{\prime \prime} \mathrm{E}$ & 54 \\
\hline 2 & Mkaytaa & 4.91 & 6.71 & 1264 & $34^{0} \quad 33^{\prime} 26^{\prime \prime} \mathrm{N}$ & $35^{0} 59^{\prime} 39^{\prime \prime} \mathrm{E}$ & 0 \\
\hline 3 & Qaabrin & 5.32 & 7.15 & 232 & $34^{0} 34^{\prime} 25^{\prime \prime} \mathrm{N}$ & $36^{0} 00^{\prime} 54^{\prime \prime} \mathrm{E}$ & 24 \\
\hline 4 & Tall Maayen & 5.82 & 6.83 & 1154 & $34^{0} 35^{\prime} 27^{\prime \prime} \mathrm{N}$ & $36^{0} 02^{\prime} 25^{\prime \prime} \mathrm{E}$ & 58 \\
\hline 5 & BallanetEl Hissa & 5.27 & 6.92 & 906 & $34^{0} 35^{\prime} 51^{\prime \prime} \mathrm{N}$ & $36^{0} 02^{\prime} 35^{\prime \prime} \mathrm{E}$ & 59 \\
\hline 6 & Al Hissa & 5.55 & 6.88 & 1245 & $34^{0} 35^{\prime} 21^{\prime \prime} \mathrm{N}$ & $36^{0} 03^{\prime} 22^{\prime \prime} \mathrm{E}$ & 107 \\
\hline 7 & Tal Andi & 3.93 & 6.81 & 2505 & $34^{0} 36^{\prime} 33^{\prime \prime} \mathrm{N}$ & $36^{0} 04^{\prime} 24^{\prime \prime} \mathrm{E}$ & 54 \\
\hline 8 & Al ChaykhAyach & 4.19 & 7.28 & 783 & $34^{0} 37^{\prime} 28^{\prime \prime} \mathrm{N}$ & $36^{0} 05^{\prime} 18^{\prime \prime} \mathrm{E}$ & 140 \\
\hline 9 & Tal Biri & n.d* & 7.22 & 868 & $34^{0} 35^{\prime} 04^{\prime \prime} \mathrm{N}$ & $36^{0} 03^{\prime} 54^{\prime \prime} \mathrm{E}$ & 188 \\
\hline 10 & Tal Abbas El Gharbi & n.d & 7.43 & 660 & $34^{0} 34^{\prime} 27^{\prime \prime} \mathrm{N}$ & $36^{0} 04^{\prime} 38^{\prime \prime} \mathrm{E}$ & 181 \\
\hline 11 & Kwaykhat & n.d & 7.45 & 586 & $34^{0} 34^{\prime} 27^{\prime \prime} \mathrm{N}$ & $36^{0} 05^{\prime} 22^{\prime \prime} \mathrm{E}$ & 260 \\
\hline 12 & Tal Abbas El Charki & n.d & 7.48 & 716 & $34^{0} 35^{\prime} 18^{\prime \prime} \mathrm{N}$ & $36^{0} 04^{\prime} 41^{\prime \prime} \mathrm{E}$ & 257 \\
\hline
\end{tabular}

*: n.d: not determined 
Traces metals are introduced in the environment through natural or anthropogenic sources. While parent rocks and metallic minerals dominate the natural sources, the anthropogenic sources range from agriculture (fertilizers, pesticides, etc.), metallurgy (mining, melting, etc.) and energy production (leaded gasoline, battery manufacture, power plants, etc.) [38][3]. Contamination of the groundwater and soil with heavy metals leads to accumulation of these substances in the human body through drinking water, pathway exposure, and by the food chain. Long-term exposure to these species can cause adverse health effects [39]. Furthermore, risks to human health associated with the contamination of groundwater by organic pollutants have been reported in this area [26]. The results of metals analyses of the 12 groundwater samples are shown in figure 2. The elemental concentrations are given in microgram per liter. For the major elements, the results indicate a decreasing trend of metals as $\mathrm{Mn}>\mathrm{Zn}>\mathrm{Pb}>\mathrm{Cd}>\mathrm{Cu}$ respectively $230,120,3.35,2.67,0.69, \mu \mathrm{g} / \mathrm{l}$ of groundwater.
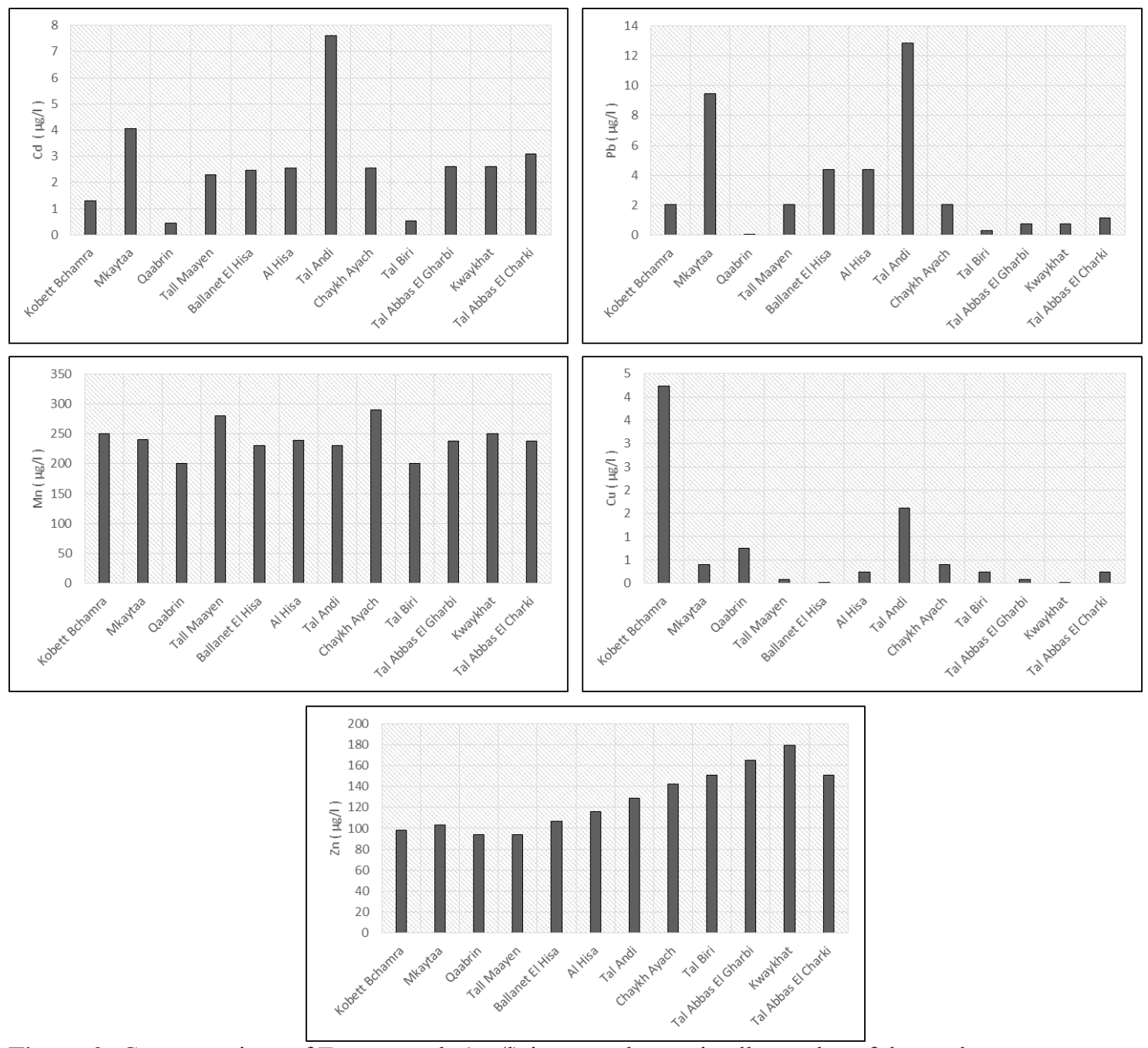

Figure 2: Concentrations of Trace metals $(\mu \mathrm{g} / \mathrm{l})$ in groundwater in all samples of the study area

Cadmium is a non-essential element frequently used in various industrial activities [40]. It is also found in Tobacco, and used in agricultural products like fertilizers. Cadmium compounds are classified as a human carcinogen (Group 2A) by IRAC. The Guideline value established by [41] for Cadmium in drinking-water is $3 \mu \mathrm{g} / \mathrm{l}$. in our study, the average concentration of Cd was $2.6 \mu \mathrm{g} / \mathrm{l}$. The highest value was observed in Tal Andi $(7.5 \mu \mathrm{g} / \mathrm{l})$ which is $~ 2.5$ times higher than the WHO standard [41]. The majority of sites showed moderate contamination of $\mathrm{Cd}$. This might be attributed to the intensive use of fertilizers in the area [25][26][5].

Manganese is used mainly in metallurgical processes, manufacturing of batteries, and in cleaning/disinfection products. Although Mn is considered an essential element for humans and animals, there have been epidemiological studies that report adverse neurological effects following extended exposure to very high levels in drinking water [41][42]. The level of Mn was similar in all our samples with a mean value of about $240 \mu \mathrm{g} / \mathrm{l}$. These concentrations were below the health-based value of $0.4 \mathrm{mg} / \mathrm{l}$ for manganese [41].

Zinc is an essential trace element found in virtually all food and potable water. The derivation of a limit value is not established for Zn. However, drinking-water containing Zinc at levels above $3 \mathrm{mg} / \mathrm{l}$ may not be acceptable to consumers [41][42]. The average concentrations of $\mathrm{Zn}$ in the twelve samples was $120 \mu \mathrm{g} / \mathrm{l}$, it is ranging between $90 \mu \mathrm{g} / \mathrm{l}$ and $170 \mu \mathrm{g} / \mathrm{l}$ at Qaabrin and Al Kouikhat, respectively.

Copper is used in metal production, batteries, wood preservatives, and building materials. Copper compounds are also used as or in fungicides, algaecide, insecticides, and fertilizers [43][44]. Copper is both an essential nutrient and a drinking-water contaminant. It can cause acute gastrointestinal effects in humans [45]. The United States Environmental Protection Agency 1991 
(USEPA) classifies copper as Group D with a provisional guideline value of $2 \mathrm{mg} / \mathrm{l}$. The mean value of Cu in our samples was $0.69 \mu \mathrm{g} / \mathrm{l}$. All $\mathrm{Cu}$ concentrations detected were under the EPA standard for drinking water $1 \mathrm{mg} / \mathrm{l}$ [46].

Lead has many different sources like agricultural, domestic, and industrial applications. It affects the reproductive system [47], the cardiovascular system, the gastrointestinal system, and the nervous system [48][49], is considered as a probable human carcinogen by IARC, with a provisional guideline of $(10 \mu \mathrm{g} / \mathrm{l})$ [41]. The mean concentration of lead in our samples was $3.3 \mu \mathrm{g} / \mathrm{l}$, with a maximum concentration of $12.8 \mu \mathrm{g} / \mathrm{l}$ at Tall Andi, which was much higher than WHO limits for drinking water $(10 \mu \mathrm{g} / \mathrm{l})$. This could be due to the effect of atmospheric deposition from the international road. It could also be due to the irrigation by wastewater, and/or the intensive usage of fertilizers in the area [50][51].

Table 2 represents the concentrations of ETM of groundwater in the study area compared with the results of similar research.

Table 2: Metal concentration in groundwater from different sites.

\begin{tabular}{|c|c|c|c|c|c|}
\hline \multirow{2}{*}{ Site } & \multicolumn{3}{|c|}{ Metals in Groundwater $(\boldsymbol{\mu g} / \mathbf{l})$} & \multirow{2}{*}{ References } \\
\cline { 2 - 5 } & $\mathbf{C d}$ & $\mathbf{P b}$ & $\mathbf{C u}$ & 130 & This study \\
\hline Akkar-Lebanon & 2.67 & 3.67 & 0.83 & 123.83 & {$[22]$} \\
\hline Bekaa-Lebanon & 0.04 & 0.74 & - & - & {$[52]$} \\
\hline KSA & - & 217 & 0.717 & -652 & {$[53]$} \\
\hline Iran & 0.216 & 0.435 & 68.75 & - & {$[42]$} \\
\hline Nigeria & 23.75 & 505.75 & & \\
\hline
\end{tabular}

\section{The heavy metal pollution index}

Quality indices are a useful way to assess the composite influence of overall pollution in drinking water regarding heavy metals [54]. In the present paper, the indices of water quality pollution were calculated after determining their concentration using the heavy metal pollution index (HPI) [55][42]. HPI is calculated according to Eqs. (1) and (2) as follows:

$$
\begin{aligned}
& \text { HPI }=\frac{\sum_{i=1}^{n} W_{i} \cdot Q_{i}^{i}}{\sum_{i=1}^{n} W_{i}}(1) \\
& \text { Qi }=\sum_{i=1}^{n} \frac{M_{i}(-) r i}{S i-I i} * 100
\end{aligned}
$$

Where $\mathrm{Q}_{\mathrm{i}}$ is the sub-index of the ith parameter and $\mathrm{Wi}$ is the unit weight age of the ith parameter, $\mathrm{N}$ is the number of parameters studied. Mi, Ii, and Si are the monitored values of the parameters, ideal and standard values of the ith parameter, respectively in ppb (table 3) [57]. The sign (-) indicates the numerical differences between the two values, regardless of the algebraic sign. Generally, the critical pollution index value is 100 .

\section{Heavy metal evaluation index (HEI)}

HEI is a method used to estimate water quality with a focus on heavy metals by many researchers [55][42]. The HEI was computed using the following expression (3):

$\mathrm{HEI}=\sum_{\mathrm{i}=1}^{\mathrm{n}} \frac{H_{c}}{H_{\max }}(3)$

Where $\mathrm{Hc}$ is the monitored values and Hmac is the maximum admissible concentration of the ith parameter according to the [41] guidelines for drinking water. The classifications of the HEI index is as follows: low (less than 10), medium (between 10 and 20), and high (more than 20). Tables 3 show the used constants for the calculation of HPI and HEI.

Table 3: Applied parameters and constants for the calculation of indices computation according to [41] for (Hmac) and Indian (Si, Ii, and Wi) guidelines for drinking water [57].

\begin{tabular}{|c|c|c|c|c|}
\hline & & Indian 2012 & & WHO 2017 \\
\hline & Si & Ii & Wi & Hmac \\
\hline Cd & 3 & & 0.33 & 3 \\
\hline $\mathbf{P b}$ & 10 & & 0.1 & 1.5 \\
\hline $\mathbf{M n}$ & 300 & 100 & 0.0033 & 50 \\
\hline $\mathbf{C u}$ & 1500 & 50 & 0.0006 & 1000 \\
\hline $\mathbf{Z n}$ & 15000 & 5000 & 0.00006 & 5000 \\
\hline
\end{tabular}

The HPI and HEI of each sampling point were calculated separately (Table 4) to compare the quality of water at each groundwater sampling location with respect to the studied metals. 
Table 4: HPI and HEI index of heavy metals in groundwater of study area.

\begin{tabular}{|c|c|c|c|c|}
\hline Site & HPI & HPI Classification & HEI value & HEI Classification \\
\hline Kobett Bchamra & 37.45 & Low heavy metals & 1.84 & Low heavy metals \\
\hline Mkaytaa & 123.93 & High heavy metals & 7.70 & Low heavy metals \\
\hline Qaabrin & 11.40 & Low heavy metals & 0.18 & Low heavy metals \\
\hline Tall Maayen & 62.82 & Low heavy metals & 2.17 & Low heavy metals \\
\hline Ballanet El Hisa & 72.08 & Low heavy metals & 3.77 & Low heavy metals \\
\hline Al Hisa & 74.72 & Low heavy metals & 3.81 & Medium heavy metals \\
\hline Tal Andi & 221.14 & High heavy metals & 11.12 & Low heavy metals \\
\hline ChaykhAyach & 69.41 & Low heavy metals & 2.27 & Low heavy metals \\
\hline Tal Biri & 14.38 & Low heavy metals & 0.42 & Low heavy metals \\
\hline Tal Abbas El Gharbi & 67.75 & Low heavy metals & 1.41 & Low heavy metals \\
\hline Kwaykhat & 67.75 & Low heavy metals & 1.41 & Low heavy metals \\
\hline Tal Abbas El Charki & 80.94 & Low heavy metals & 1.86 &
\end{tabular}

The computed HPI values ranged from 11.4 to 221.1. The highest measured values of HPI above the critical index (100) of the groundwater were seen in Tal Andi (221) and Mkaytaa (123.9). The HPI values of groundwater at the other sites were below the critical index value, with Qaabrine, Tal Biri and Kobbet Bchamra having a much lower value than the other sampling points. The HEI values ranged from 0.18 to 11.1. The highest value (11.1) measured in Tal Andi is classified as medium heavy metals. The other sites had an HEI value around 2 except in Mkaytaa (7.7). The HPI and HEI show similar trends at the various sampling points (Tab.5). The HPI of this study (mean: 75.3) were lower than those in Bangladesh [59], and in India [55], 1497.4, and 1304.6 respectively. They were also higher than those observed in Nigeria (12.9) [42]. Our HEI values (mean: 3.2) in drinking water are lower than those found by [55] and [42] respectively in India (45.8) and Nigeria (367).

Table 5: Comparison of calculated indices in Akkar groundwater with different area

\begin{tabular}{|c|c|c|c|c|c|c|}
\hline Index & Akkar Min & Akkar Max & Akkar mean & Bangladesh & India & Nigeria \\
\hline HPI & 11.4 & 221.1 & 75.3 & 1497.4 & 1304.6 & 12.9 \\
\hline Classification & LHM & HHM & LHM & HHM & HHM & LHM \\
\hline HEI & 0.18 & 11.1 & 3.16 & 41 & 45.8 & 367 \\
\hline Classification & LHM & MHM & LHM & HHM & HHM & HHM \\
\hline
\end{tabular}

LHM: low heavy metals, MHM: Medium heavy-metals, HHM: High heavy metals.

\section{Soil Analyses}

Trace metals reach the soil through the application of agricultural chemicals, burning fossil fuels, sewage sludges and traffic fumes where they can remain there and slowly accumulating over time [60]. Stated that surface layers of the soil may accumulate large amounts of heavy metals which affect sensitive plants growing in the soil. But the intensity of this pollution depends primarily on the physic-chemical properties of soil, the nature and amount of trace metals, their geo availability [61], and their stability in the environment. However, Akkar plain considered as an agricultural area where the anthropogenic sources of traces metals may be mainly originated from urban effluent, vehicle exhausts, pesticides and fertilizers applications [26][62][63].

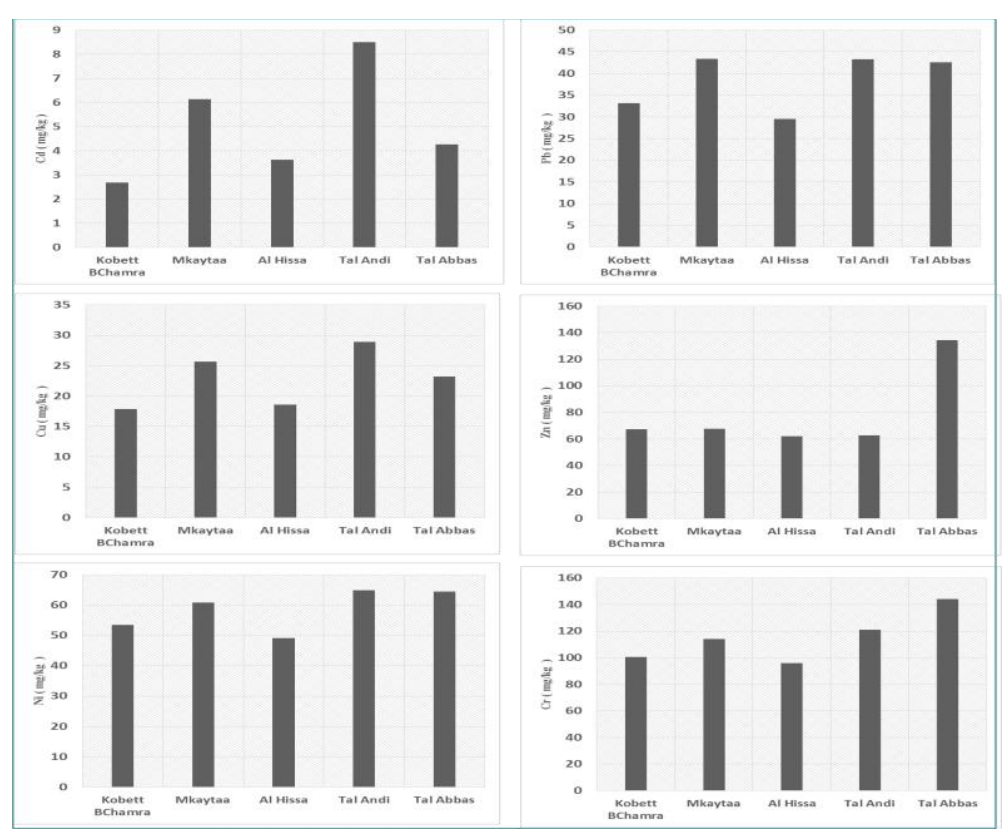

Figure 3: Trace element concentrations $\mathrm{mg} / \mathrm{kg}$ in five samples soil at Akkar plain. 
The concentrations values determined in the soil samples for $\mathrm{Cd}, \mathrm{Cr}, \mathrm{Cu}, \mathrm{Ni}, \mathrm{Pb}$, and $\mathrm{Zn}$ are reported in figure 3 where each concentration value is the mean of two extraction replicates.In Akkar soil, the concentration of $\mathrm{Pb}$ ranging between $29-43 \mathrm{mg} / \mathrm{kg}$ d.w. The maximum value was reported at Tal Andi. High levels of $\mathrm{Cu}$ are observed in Tal Andi $28.9 \mathrm{mg} / \mathrm{kg}$ d.w. The concentration of Cd varied between 2.6 in Kobbet Bchamra and $8.5 \mathrm{mg} / \mathrm{kg}$ in Tal Andi. Zn, is an essential trace metal for the biological system of soils and relatively non-toxic to humans and biota at low levels [64]. Its levels in the soil of Akkar varied from 61 to $134 \mathrm{mg} / \mathrm{kg}$ d.w. Tal Andi and Tal Abbas. Soil are largely contaminated with a concentration of Ni exceeding $60 \mathrm{mg} / \mathrm{kg}$. Cr concertation in all samples varied between $95 \mathrm{mg} / \mathrm{kg}$ d.w in Al Hissa and $144 \mathrm{mg} / \mathrm{kg}$ d.w in Tal Abbas.

\section{Enrichment factor}

Many authors use the enrichment factor (EF) to determine whether the sources of the metals are geogenic and/or anthropogenic [35][65]. The EF formula uses an internal reference, known as a normalizer geochemical markers (e.g. Al, Fe) to moderate the mineralogical and grain size variations of samples [66]. The average shale values reported by [67] are often used as background reference values [66]. EF is calculated according to formula as follows (4):

\section{$E F=\frac{[\mathrm{Mle}] \text { sample f [A1] sample }}{[\mathrm{Me}] \text { Background }[\text { [Al] Background }}$}

Five contamination categories are defined by [68]: EF <2, deficiency to low enrichment; EF 2-5, moderate enrichment; EF 520, significant enrichment; EF 20-40,very high enrichment; and EF >40, extremely high enrichment.

The calculated $\mathrm{EF}$ values presented in figure 4 suggest a low enrichment and a natural origin of the metal for $\mathrm{Cu}(0.8-1.3), \mathrm{Zn}$ (0.14-0.3), a moderate enrichment concerning Cr (1.9-2.8) Ni (1.7-2.4) Pb (2.6-4). EF of Cd was very high compared to other metals and varied from 25 to 50 with an average of 25.51 which correspond to a very high enrichment. The highest EF values were found in Tal Andi which was an extremely high enriched with cadmium (52) and moderately enriched in $\mathrm{Pb}(\mathrm{EF}=4)$ and $\mathrm{Ni}$ $(\mathrm{EF}=2.4)$ and $\mathrm{Cr}(\mathrm{EF}=2.5)$. The elevated values indicate that the studied area may be affected by human activities such as the use of pesticides containing impurities of Cd [62][69][70].

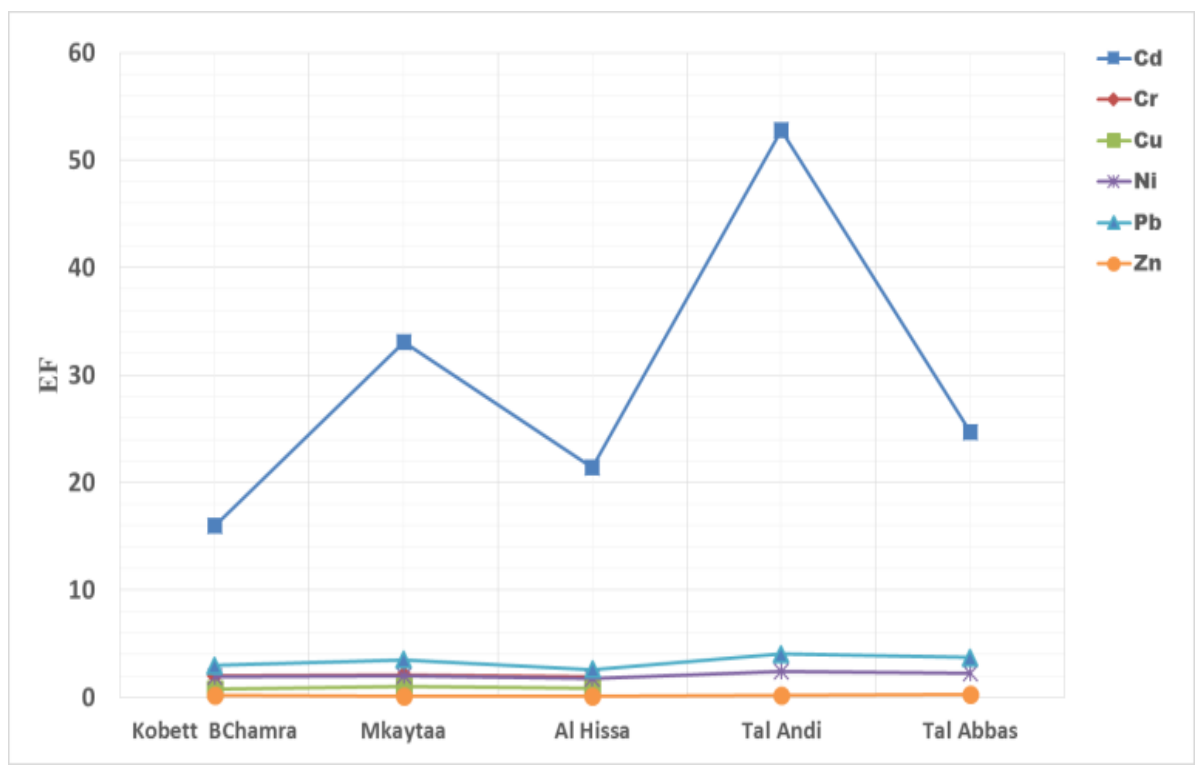

Figure 4: Profiles of the computed enrichment factor (EF) in the soil of the study area.

Geoaccumulation index (Igeo)

Igeo is an index introduced by [71] used to evaluate the contamination levels of heavy metals in agricultural soils. Igeo is calculated according to formula as follows (5):

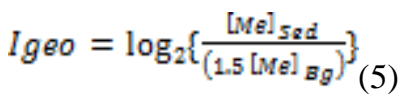

Where $[\mathrm{Me}]_{\mathrm{Sed}}$ is the measured concentration of the element in the soil sample and $[\mathrm{Me}]_{\mathrm{Bg}}$ is the geochemical background concentration of the same metal.

In this study, Igeo has been calculated using background Geochemical values of soil metal concentrations reported by [51]. where the land is characterized by a Quaternary arable [72]. The factor (1.5) is used to address possible variations in the background concentration due to lithologic differences [73]. Igeo values are classified from class 0 to class 6 according to Ruiz's classification [74] (table 6). 
Table 6: Classification of geoaccumulation index values.

\begin{tabular}{|c|c|c|}
\hline Class & I geao Value & Quality \\
\hline 0 & I geao $\leq 0$ & Uncontaminated \\
\hline 1 & $0<$ I geao $<1$ & Uncontaminated to moderately contaminated \\
\hline 2 & $1<$ I geao $<2$ & Moderately contaminated \\
\hline 3 & $2<$ I geao $<3$ & Heavily contaminated \\
\hline 4 & $3<$ I geao $<4$ & Heavily to extremely contaminated \\
\hline 5 & $4<$ I geao $<5$ & Extremely contaminated \\
\hline 6 & $5<$ I geao & inter \\
\hline
\end{tabular}

In general $\mathrm{Ni}$ and $\mathrm{Zn}$ appear to be uncontaminated elements in all the sites with a Igeo negative values, while $\mathrm{Cu}$ has Igeo values between 0 and 1; therefore depicting uncontaminated to moderately contaminated soil, whereas Pb showed a maximum values of Igeo between 2 and 3 thus, indicating moderately to heavily contaminated soil in all sites.

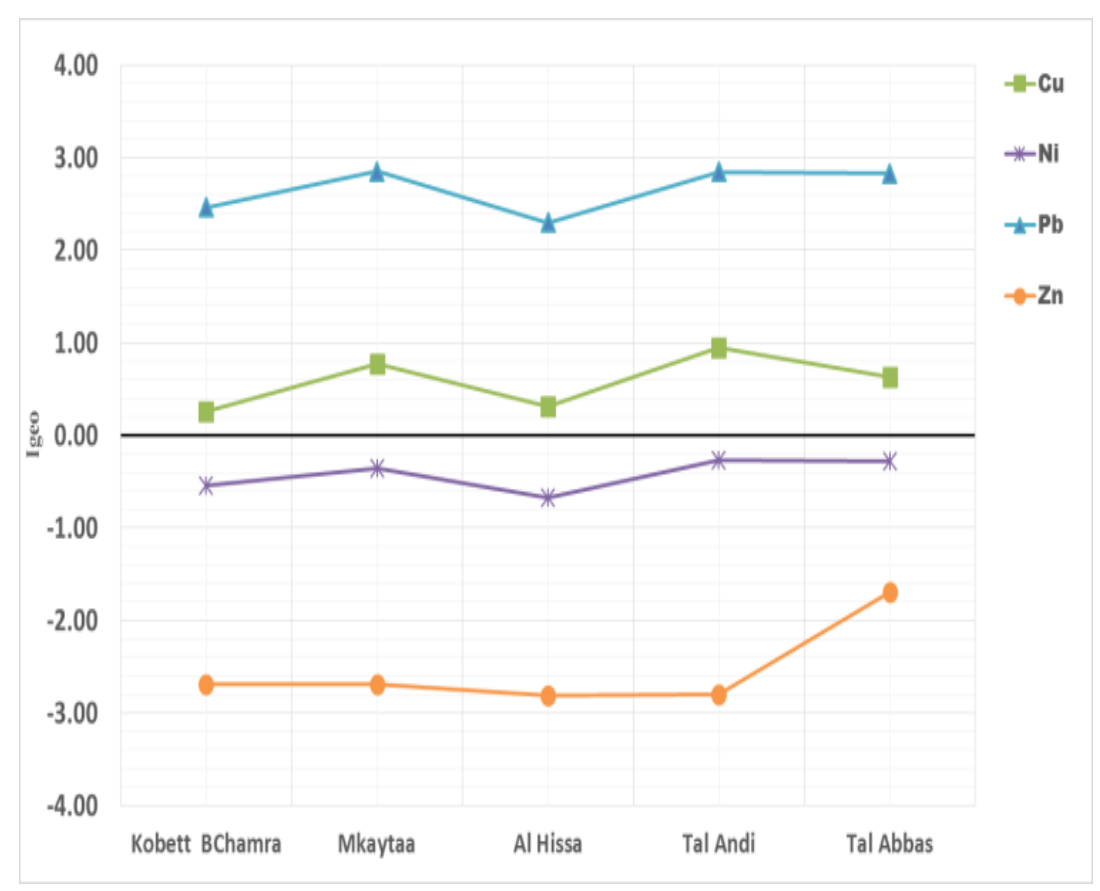

Figure 5: Profiles of geoaccumulation index in the soil of the study area.

\section{CONCLUSION}

Examining the results of the present study we found fluctuations in a concentration of various heavy metals in different sites. The mean concentration of the heavy metals of groundwater in the order: $\mathrm{Mn}>\mathrm{Zn}>\mathrm{Pb}>\mathrm{Cd}>\mathrm{Cu}$ respectively 230, 120, 3.35, 2.67 and $0.69, \mu \mathrm{g} / \mathrm{l}$. It indicated that although the groundwater at the study site was likely affected by leaching of heavy metals especially cadmium and lead from the agriculture activities (wastewater irrigation, fertilizers, and pesticides). The metal analysis showed that the samples of groundwater water in some sites including El Mkaytaa, Tal Andi and Tal Abbas El Charki were not suitable as drinking water compared to the WHO standard with an elevated concentration in $\mathrm{Cd}$ and $\mathrm{Pb}$. But in the other sites, it is safe as drinking water at least in terms of heavy metals. Examining the distribution of concentration values of elements we observe that $\mathrm{Cd}$ represents the highest median concentration, followed by $\mathrm{Pb}$ and $\mathrm{Cr}$. According to calculations of enrichment factors, and geoaccumulation index the elements $\mathrm{Pb}, \mathrm{Cr}$ are of moderate enrichment, while $\mathrm{Cd}$ has the highest level of enrichment with an EF value of over 50. Other elements are at background concentrations. The revelations during the present study summons attention from the local authorities and farmers to optimize utilization of agriculture fertilizers and pesticides, and stop using wastewater for irrigation.

\section{ACKNOWLEDGMENTS}

We acknowledge the support from the Doctoral School for science and technology-AZM center at Lebanese University, DSST-LU.

\section{REFERENCES}

[1] M. S. Islam, M. K. Ahmed, M. Raknuzzaman, M. Habibullah-Al-Mamun, and S. Masunaga, "Metal speciation in sediment and their bioaccumulation in fish species of three urban rivers in Bangladesh," Arch. Environ. Contam. Toxicol., vol. 68, no. 1, pp. 92-106, 2015. 
[2] E. Uluturhan, A. Kontas, and E. Can, "Sediment concentrations of heavy metals in the Homa Lagoon (Eastern Aegean Sea): assessment of contamination and ecological risks," Mar. Pollut. Bull., vol. 62, no. 9, pp. 1989-1997, 2011.

[3] M. Wang, R. Liu, W. Chen, C. Peng, and B. Markert, "Effects of urbanization on heavy metal accumulation in surface soils, Beijing," J. Environ. Sci. (China), vol. 64, pp. 328-334, 2018.

[4] I. R. Santos, E. V Silva-Filho, C. E. G. R. Schaefer, M. R. Albuquerque-Filho, and L. S. Campos, "Heavy metal contamination in coastal sediments and soils near the Brazilian Antarctic Station, King George Island," Mar. Pollut. Bull., vol. 50, no. 2, pp. 185-194, 2005.

[5] D. Naghipour, S. D. Ashrafi, and K. Taghavi, "Data of heavy metals in soil and groundwater at Kiwi gardens of Amlash in Guilan Province, Iran," Data Br., vol. 18, pp. 1556-1561, 2018.

[6] Z. Li, Z. Ma, T. J. van der Kuijp, Z. Yuan, and L. Huang, "A review of soil heavy metal pollution from mines in China: pollution and health risk assessment," Sci. Total Environ., vol. 468, pp. 843-853, 2014.

[7] Q. Liu, Y. Liu, and M. Zhang, "Mercury and cadmium contamination in traffic soil of Beijing, China," Bull. Environ. Contam. Toxicol., vol. 88, no. 2, pp. 154-157, 2012.

[8] H. U. Ke-Lin, F.-R. Zhang, L. Hong, F. Huang, and L. I. Bao-Guo, "Spatial Patterns of Soil Heavy Metals in Urban-Rural Transition Zone of Beijing1," Pedosphere, vol. 16, no. 6, pp. 690-698, 2006.

[9] C. Pagotto, N. Remy, M. Legret, and P. Le Cloirec, "Heavy metal pollution of road dust and roadside soil near a major rural highway," Environ. Technol., vol. 22, no. 3, pp. 307-319, 2001.

[10] L. Herngren, A. Goonetilleke, and G. A. Ayoko, "Understanding heavy metal and suspended solids relationships in urban stormwater using simulated rainfall," J. Environ. Manage., vol. 76, no. 2, pp. 149-158, 2005.

[11] Y. Wang et al., "Kinetics comparison on simultaneous and sequential competitive adsorption of heavy metals in red soils," J. Cent. South Univ., vol. 22, no. 4, pp. 1269-1275, 2015.

[12] M. Adrees et al., "Mechanisms of silicon-mediated alleviation of heavy metal toxicity in plants: a review," Ecotoxicol. Environ. Saf., vol. 119, pp. 186-197, 2015.

[13] S. Ai et al., "Temporal variations and spatial distributions of heavy metals in a wastewater-irrigated soil-eggplant system and associated influencing factors," Ecotoxicol. Environ. Saf., vol. 153, no. January, pp. 204-214, 2018.

[14] D. Hou, D. O’Connor, P. Nathanail, L. Tian, and Y. Ma, "Integrated GIS and multivariate statistical analysis for regional scale assessment of heavy metal soil contamination: A critical review," Environ. Pollut., vol. 231, pp. 1188-1200, 2017.

[15] B. J. Alloway, "Sources of heavy metals and metalloids in soils," in Heavy metals in soils, Springer, 2013 , pp. 11-50.

[16] A. Burges, L. Epelde, and C. Garbisu, "Impact of repeated single-metal and multi-metal pollution events on soil quality," Chemosphere, vol. 120, pp. 8-15, 2015.

[17] N. Kaloustian and Y. Diab, "Effects of urbanization on the urban heat island in Beirut," Urban Clim., vol. 14, pp. 154$165,2015$.

[18] Lebanese Ministry of Agriculture and O. O. I. C. (FAO), Food and Agriculture Organization of the United Nations, "GLOBAL RESULTS OF BASIC MODULE CENSUS OF AGRICULTURE 2010," 2012.

[19] A. Abdel-Rahman and F. H. Nader, "Characterization of the Lebanese Jurassic-Cretaceous carbonate stratigraphic sequence: a geochemical approach," Geol. J., vol. 37, no. 1, pp. 69-91, 2002.

[20] M. Abdulrazzak and L. Kobeissi, "UNDP-ESCWA initiative on national framework for water resources management in Lebanon," UN-House-Beirut, Lebanon, 2002.

[21] M. El-Fadel, R. Khoury, A. Abou-Ibrahim, M. Zeinati, H. Sbayti, and E. Bou-Zeid, "Preliminary characterization of Lebanese coastal waters," 2000.

[22] B. R. Darwish T.M, Jomaa I., Awada M, "Preliminary Contamination Hazard Assessment of Land Ressources in Central Bekaa Plain of Lebanon," Leban. Sci. J., vol. 9, no. 2, pp. 1-58, 2008.

[23] G. KHALAF, K. SLIM, Z. SAAD, and K. NAKHLE, "Evaluation de la qualit \{é\} biologique des eaux du Nahr el Jaouz (Liban): application des $\mathrm{m}\{$ é\}thodes indicielles," Bull. Mens. la Soci\{é\}t\{é\} linn\{é\}enne Lyon, vol. 76, no. 9-10, pp. 255$268,2007$.

[24] D. Geara-matta et al., "State of Art about water uses and wastewater management in Lebanon To cite this version: HAL Id : hal-00521446 State of Art about water uses and wastewater management in Lebanon," 2010.

[25] M. Baroudi, H. Bakkour, J. Halwani, S. Taha, R. El-Osmani, and A. H. Mouneimne, "Determination of pesticide, nitrates and nitrites level in groundwater of akkar plain in north Lebanon," J. Appl. Sci. Res, vol. 8, no. 8, pp. 4663-4667, 2012.

[26] C. CHBIB, "Pollution des sols et des eaux souterraines par les pesticides dans la région d'Akkar au nord du Liban: Evaluation des risques sanitaires.," Université Libanaise, Université de Lille, 2017.

[27] R. El-Osmani, S. Net, D. Dumoulin, M. Baroudi, H. Bakkour, and B. Ouddane, "Solid phase extraction of organochlorine pesticides residues in groundwater (akkar plain, north Lebanon)," Int. J. Environ. Res., vol. 8, no. 4, pp. 903-912, 2014.

[28] O. El Samad, R. Baydoun, B. Nsouli, and T. Darwish, "Determination of natural and artificial radioactivity in soil at North Lebanon province," J. Environ. Radioact., vol. 125, pp. 36-39, 2013.

[29] Z. Saad, V. Kazpard, A. El Samrani, K. Slim, and P. Nabhan, "Relations entre métaux traces dans le tabac et la nature du sol au Liban," Cah. Agric., vol. 15, no. 2, pp. 203-211, 2006.

[30] C. Candeias, R. Melo, P. F. Ávila, E. F. da Silva, A. R. Salgueiro, and J. P. Teixeira, "Heavy metal pollution in mine-soilplant system in S. Francisco de Assis-Panasqueira mine (Portugal)," Appl. Geochemistry, vol. 44, pp. 12-26, 2014.

[31] C. Micó, L. Recatalá, M. Peris, and J. Sánchez, "Assessing heavy metal sources in agricultural soils of an European Mediterranean area by multivariate analysis," Chemosphere, vol. 65, no. 5, pp. 863-872, 2006.

[32] M. Ghaderpoori, B. kamarehie, A. Jafari, A. Ghaderpoury, and M. Karami, "Heavy metals analysis and quality assessment in drinking water - Khorramabad city, Iran," Data Br., vol. 16, pp. 685-692, 2018.

[33] UNHCR., "Lebanon Akkar governorate flood contingency planning for informal settlements.," 2014. 
[34] Y. Jiang and J. Yan, "Effects of land use on hydrochemistry and contamination of Karst groundwater from Nandong underground river system, China," Water, Air, Soil Pollut., vol. 210, no. 1-4, pp. 123-141, 2010.

[35] M. Hamzeh, B. Ouddane, M. El-Daye, and J. Halwani, "Profile of trace metals accumulation in core sediment from Seine river estuary (docks basin)," Environ. Technol., vol. 34, no. 9, pp. 1107-1116, 2013.

[36] U. S. Epa, "Integrated risk information system (IRIS).” EPA, 1999.

[37] J. Liu, X.-H. Zhang, H. Tran, D.-Q. Wang, and Y.-N. Zhu, "Heavy metal contamination and risk assessment in water, paddy soil, and rice around an electroplating plant," Environ. Sci. Pollut. Res., vol. 18, no. 9, p. 1623, 2011.

[38] S. Ai et al., "Temporal variations and spatial distributions of heavy metals in a wastewater-irrigated soil-eggplant system and associated influencing factors," Ecotoxicol. Environ. Saf., vol. 153, pp. 204-214, 2018.

[39] P. Wongsasuluk, S. Chotpantarat, W. Siriwong, and M. Robson, "Using hair and fingernails in binary logistic regression for bio-monitoring of heavy metals/metalloid in groundwater in intensively agricultural areas, Thailand," Environ. Res., vol. 162, no. August 2017, pp. 106-118, 2018.

[40] D. C. Adriano, "Arsenic," in Trace elements in terrestrial environments, Springer, 2001, pp. $219-261$.

[41] F. Edition, "Guidelines for drinking-water quality," WHO Chron., vol. 38, no. 4, pp. 104-108, 2011.

[42] A. E. Edet and O. E. Offiong, "Evaluation of water quality pollution indices for heavy metal contamination monitoring. A study case from Akpabuyo-Odukpani area, Lower Cross River Basin (southeastern Nigeria)," GeoJournal, 2002.

[43] L. Landner and L. Lindeström, Copper in society and in the environment: an account of the facts on fluxes, amounts and effects of copper in Sweden. Swedish Environmental Research Group [Svenska miljöforskargruppen], 1999.

[44] ATSDR, "Toxicological Profile for Copper (Draft for Public Comment), US Department of Health and Human Services, Public Health Service, Agency for Toxic Substances and Disease Registry (Subcontract No. ATSDR-205-1999-00024), Atlanta, GA," 2002.

[45] World Health Orgnization (WHO), "Copper in Drinking-water," p. 23, 2004.

[46] U. Environmental Protection Agency and O. of Water, "2018 Edition of the Drinking Water Standards and Health Advisories Tables (EPA 822-F-18-001)," no. March, p. 20, 2018.

[47] P. Apostoli, P. Kiss, S. Porru, J. P. Bonde, and M. Vanhoorne, "Male reproductive toxicity of lead in animals and humans. ASCLEPIOS Study Group.," Occup. Environ. Med., vol. 55, no. 6, pp. 364-374, 1998.

[48] S. Agarwal, T. Zaman, E. Murat Tuzcu, and S. R. Kapadia, "Heavy metals and cardiovascular disease: results from the National Health and Nutrition Examination Survey (NHANES) 1999-2006," Angiology, vol. 62, no. 5, pp. 422-429, 2011.

[49] L. Patrick, "Lead Toxicity, a review of the literature. Part I: Exposure, Evaluation, and treatment.," Altern. Med. Rev., vol. 11, no. 1, 2006.

[50] E. Abi Rizk, "Evolution du trait de côte libanais entre 1962 et 2003,” no. 2005, pp. 169-178, 2005.

[51] B. Nsouli, T. Darwish, J. P. Thomas, K. Zahraman, and M. Roumié, "Ni, $\mathrm{Cu}, \mathrm{Zn}$ and Pb background values determination in representative Lebanese soil using the thick target PIXE technique," Nucl. Instruments Methods Phys. Res. Sect. B Beam Interact. with Mater. Atoms, vol. 219-220, no. 1-4, pp. 181-186, 2004.

[52] F. A. Alseroury, T. Almeelbi, A. Khan, M. A. Barakata, J. H. Al-Zahrani, and W. Alali, "Estimation of natural radioactive and heavy metals concentration in underground water," J. Radiat. Res. Appl. Sci., vol. in press, no. July, pp. 0-1, 2018.

[53] E. Cheshmazar, H. Arfaeinia, K. Karimyan, H. Sharafi, and S. E. Hashemi, "Dataset for effect comparison of irrigation by wastewater and ground water on amount of heavy metals in soil and vegetables: Accumulation, transfer factor and health risk assessment," Data Br., vol. 18, pp. 1702-1710, 2018.

[54] S. H. Dizgah, K. Taghavi, J. Jaafari, E. Roohbakhsh, and S. D. Ashrafi, "Data on pollutants content in the influent and effluent from wastewater treatment plant of Rasht in Guilan Province, Iran,” Data Br., vol. 16, pp. 271-275, 2018.

[55] O. S. Brraich and S. Jangu, "Evaluation of water quality pollution indices for heavy metal contamination monitoring in the water of Harike Wetland (Ramsar Site), India," Int. J. Sci. Res. Publ., vol. 5, no. 2, pp. 1-6, 2015.

[56] R. Mead, C. J. Phene, D. W. Meek, and E. Science, "Journal of Environmental Science and Health . Part A: Environmental Science and Engineering and Toxicology: Toxic / Hazardous Substances and Environmental Engineering Relations between phosphorus in drip irrigation water and selenium uptake by wild must," no. April 2013, pp. 283-297, 2008.

[57] IS-10500, "Indian Standard, Drinking Water-specification,” vol. Second Rev, no. May, 2012, 2012.

[58] "Guidelines for drinking water quality WHO 4th edition wz edit 2017new." .

[59] M. A. H. Bhuiyan, M. A. Islam, S. B. Dampare, L. Parvez, and S. Suzuki, "Evaluation of hazardous metal pollution in irrigation and drinking water systems in the vicinity of a coal mine area of northwestern Bangladesh," J. Hazard. Mater., vol. 179, no. 1-3, pp. 1065-1077, 2010.

[60] A. Kabata-Pendias, "Agricultural problems related to excessive trace metal contents of soils," in Heavy metals, Springer, 1995, pp. 3-18.

[61] M. B. Rivera, J. C. Fernández-Caliani, and M. I. Giráldez, "Geoavailability of lithogenic trace elements of environmental concern and supergene enrichment in soils of the Sierra de Aracena Natural Park (SW Spain)," Geoderma, vol. 259, pp. 164-173, 2015.

[62] F. Z. A. MEHENNAOUI, L. Sahli, and S. Mehennaoui, "EVALUATION DE LA CONTAMINATION PAR LECADMIUM, LE PLOMB ET LE ZINC DE L'EAU, DES SEDIMENTS DE L'OUED RHUMEL ET SON AFFLUENT LE BOUMERZOUG, ET LEUR TRANSFERT VERS UNEPLANTE SEMI-AQUATIQUE: RORIPPA NASTURTIUMAQUATICUM (L.),"Sci. Technol. C, Biotechnol., no. 29, pp. 45-55, 2009.

[63] A. INERIS, "Guide pour l'inventaire des émissions, rejets et pertes de micropolluants vers les eaux de surface,” DRC-17136877-04137A, INERIS. ed. INERIS, 2017. 
[64] L. M. Plum, L. Rink, and H. Haase, "The essential toxin: impact of zinc on human health," Int. J. Environ. Res. Public Health, vol. 7, no. 4, pp. 1342-1365, 2010.

[65] L. Leleyter, C. Rousseau, L. Biree, and F. Baraud, "Comparison of EDTA, HCl and sequential extraction procedures, for selected metals ( $\mathrm{Cu}, \mathrm{Mn}, \mathrm{Pb}, \mathrm{Zn})$, in soils, riverine and marine sediments," J. Geochemical Explor., vol. 116, pp. 51-59, 2012.

[66] N. S. Magesh, N. Chandrasekar, and D. V. Roy, "Spatial analysis of trace element contamination in sediments of Tamiraparani estuary, southeast coast of India," Estuar. Coast. Shelf Sci., vol. 92, no. 4, pp. 618-628, 2011.

[67] K. K. Turekian and K. H. Wedepohl, "Distribution of the elements in some major units of the earth's crust," Geol. Soc. Am. Bull., vol. 72, no. 2, pp. 175-192, 1961.

[68] R. A. Sutherland, "Bed sediment-associated trace metals in an urban stream, Oahu, Hawaii," Environ. Geol., vol. 39, no. 6, pp. 611-627, 2000.

[69] P. Hlavackova, "Evaluation du comportement du cuivre et du zinc dans une matrice de type sol à l'aide de différentes méthodologies," L’institut Natl. des Sci. Appliquées Lyon, 2005.

[70] J. Marrugo-Negrete, J. Pinedo-Hernández, and S. Díez, "Assessment of heavy metal pollution, spatial distribution and origin in agricultural soils along the Sinú River Basin, Colombia,” Environ. Res., vol. 154, pp. 380-388, 2017.

[71] G. Müller, "Heavy metals and nutrients in sediments of Lake Balaton, Hungary," Environ. Technol., vol. 2, no. 1, pp. 3948, 1981.

[72] T. Darwish, P. Zdruli, R. Saliba, M. Awad, A. Shaban, and G. Faour, "Vulnerability to Desertification in Lebanon Based on Geo-information and Socioeconomic Conditions," J. Environ. Sci. Eng. B, vol. 1, no. 7B, p. 851, 2012.

[73] M. Hamzeh, B. Ouddane, M. Daye, and J. Halwani, "Trace metal mobilization from surficial sediments of the Seine River Estuary," Water, Air, Soil Pollut., vol. 225, no. 3, p. 1878, 2014.

[74] F. Ruiz, "Trace metals in estuarine sediments from the southwestern Spanish coast," Mar. Pollut. Bull., vol. 42, no. 6, pp. 481-489, 2001. 